\title{
Microglial process convergence on axonal segments in health and disease
}

\author{
Savannah D. Benusa, Audrey D. Lafrenaye \\ Department of Anatomy and Neurobiology, Virginia Commonwealth University, Richmond, VA 23298, USA. \\ Correspondence to: Dr. Audrey D. Lafrenaye, Department of Anatomy and Neurobiology, Virginia Commonwealth University \\ Medical Center, P.O. Box 980709, Richmond, VA 23298, USA. E-mail: audrey.lafrenaye@vcuhealth.org
}

How to cite this article: Benusa SD, Lafrenaye AD. Microglial process convergence on axonal segments in health and disease. Neuroimmuno/ Neuroinflammation 2020;7:23-39. http://dx.doi.org/10.20517/2347-8659.2019.28

Received: 31 Dec 2019 First Decision: 6 Feb 2020 Revised: 19 Feb 2020 Accepted: 27 Feb 2020 Published: 21 Mar 2020

Science Editor: Jeffrey Bajramovic Copy Editor: Jing-Wen Zhang Production Editor: Tian Zhang

\begin{abstract}
Microglia dynamically interact with neurons influencing the development, structure, and function of neuronal networks. Recent studies suggest microglia may also influence neuronal activity by physically interacting with axonal domains responsible for action potential initiation and propagation. However, the nature of these microglial process interactions is not well understood. Microglial-axonal contacts are present early in development and persist through adulthood, implicating microglial interactions in the regulation of axonal integrity in both the developing and mature central nervous system. Moreover, changes in microglial-axonal contact have been described in disease states such as multiple sclerosis (MS) and traumatic brain injury (TBI). Depending on the disease state, there are increased associations with specific axonal segments. In MS, there is enhanced contact with the axon initial segment and node of Ranvier, while, in TBI, microglia alter interactions with axons at the site of injury, as well as at the axon initial segment. In this article, we review the interactions of microglial processes with axonal segments, analyzing their associations with various axonal domains and how these interactions may differ between MS and TBI. Furthermore, we discuss potential functional consequences and molecular mechanisms of these interactions and how these may differ among various types of microglial-axonal interactions.
\end{abstract}

Keywords: Microglia, multiple sclerosis, traumatic brain injury, microglia-axonal interactions

\section{INTRODUCTION}

Microglia are the innate immune cells of the central nervous system (CNS) and the primary mediators of the neuroinflammatory response. They are derived from a pool of primitive macrophages from the yolk sac that appear during early embryonic development ${ }^{[1-3]}$. Microglia are ontogenetically distinct from

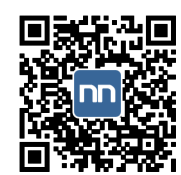


the peripheral blood-derived monocytes/macrophages that reside outside the CNS and mediate the peripheral inflammatory response ${ }^{[4,5]}$. Peripheral blood-derived immune cells are not typically found in the healthy CNS. However, peripheral monocytes/macrophages can infiltrate the CNS and exacerbate the neuroinflammatory response under pathological conditions. The distinct developmental origin of microglia from peripheral monocyte-derived macrophages and the exclusion of peripheral immune cells from the CNS underscores the immunological privilege of the CNS and the unique functions microglia might exert in the healthy brain and in pathological processes ${ }^{[6]}$.

Microglia are cells with highly dynamic process networks that rapidly remodel to survey the microenvironment and maintain tissue homeostasis ${ }^{[7-9]}$. The surveying processes of microglia respond to CNS perturbations through rapid protrusion onto the site of insult/interest ${ }^{[7,10]}$ and microglia undergo "activation", a complex series of alterations including changes in enzyme, receptor, and immune factor expression and altered cellular morphology ${ }^{[3,11,12]}$. Microglia exhibit a variety of morphologies ranging from small cell bodies with long highly-branched processes to enlarged cell bodies with short, thick processes ${ }^{[3,13]}$. The spectrum of microglial morphologies is indicative of their activation state and is commonly used to characterize activated $v s$. non-activated microglia in histological samples. Surveying (non-activated) microglia exhibit long, highly-branched or "ramified" processes that sample the surrounding environment. However, upon activation, microglia retract their processes and increase their cell body size, exhibiting morphologies defined by short, thick processes and large somas ${ }^{[3,14]}$. Highly activated, phagocytic microglia tend to lose distinctive processes all together and exhibit an ameboid shape ${ }^{[3,14]}$.

Many studies have investigated microglial-neuronal interactions via secreted factors. Activated microglia exhibit extensive changes in the expression of their inflammatory profile ${ }^{[15]}$. While some of these secreted factors may provide neurotrophic functions, pro-inflammatory factors exhibit deleterious effects ${ }^{[16,17]}$. Various neurotrophic secreted factors released from microglia induce neurite outgrowth and have been shown to be involved in regulating the cytoarchitecture of the developing brain ${ }^{[18-20]}$. Pro-inflammatory microglia, however, up-regulate cytokines and enzymes that produce reactive oxygen species, which have been implicated in axonal injury and disruption ${ }^{[16,21-32]}$.

Microglia also interact with neurons through physical contact under homeostatic conditions ${ }^{[7,9,11,33-36]}$. Microglia have recently been shown to contact dendrites and neuronal cell bodies in the normal adult brain ${ }^{[37,38]}$. Both contact types require purinergic signaling through the $\mathrm{P} 2 \mathrm{Y} 12$ receptor and appear to be protective in nature ${ }^{[37-40]}$. In the developing somatosensory cortex, it was recently found that microglial process contacts onto dendrites precipitates filipodia formation, linking microglia process contacts with synaptic formation ${ }^{[38]}$. Microglia are also key mediators of synaptic pruning, which alters the neuronal excitatory/inhibitory balance ${ }^{[4]}$. Microglia contact pre- and postsynaptic neuronal elements in an activitydependent manner, and synapses that are contacted by microglia more frequently and for longer durations of time are subsequently removed [Figure $1 \mathrm{~A}]^{[9,42,43]}$. Specifically, studies have demonstrated that early during development (Postnatal Day 5 in mice) phagocytic microglia engulf synapses of neurons with reduced activity/input in a complement-dependent manor ${ }^{[42,43]}$. Alternatively, later during development (Postnatal Day 15 in mice) microglia only appear to remove parts of synapses in a process called "trogocytosis"[44]. Another study using zebrafish larva demonstrated that microglial-synaptic contacts increased with increased neuronal spontaneous activity. Further, the zebrafish neurons that were contacted by microglia exhibited a decrease in activity, while noncontacted neurons maintained an increased firing rate $^{[36]}$.

Microglia may also influence neuronal excitability through contact with the axon initial segment (AIS), the axonal domain responsible for action potential initiation and modulation [Figure $1 \mathrm{~A}]^{[45]}$. Microglia appear to establish contact with the AIS early in development and maintain this contact through adulthood, 


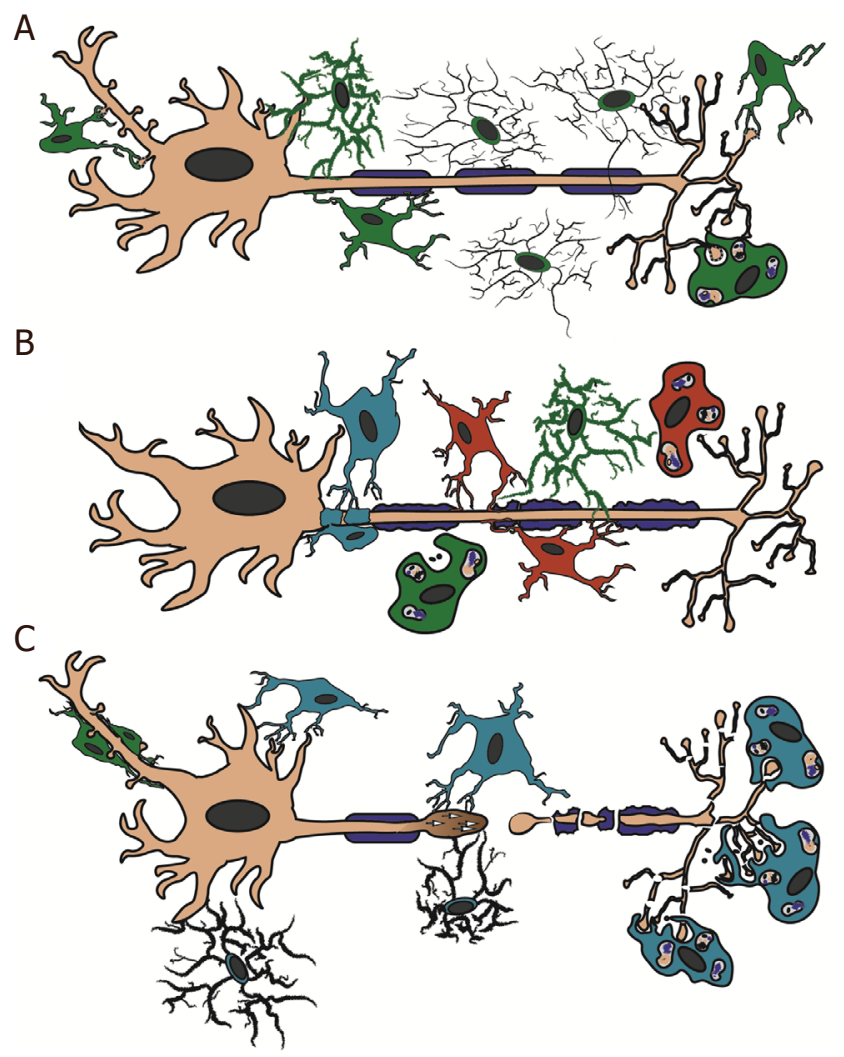

Figure 1. Schematic representation of microglial process contacts in health and disease. Illustration demonstrating various microglial and monocytic contacts onto axonal segments. A: in the healthy brain, resident microglia (green) contact the neuronal cell body and axon initial segment. These microglia potentially express TNF- $\alpha$ and CSF1 and are involved in reduction of hyperexcitability in neurons. The dynamic surveying processes of non-activated ramified microglia also contact various areas of the axon in the healthy CNS. During development, contacts by resident microglia are involved in pre- and postsynaptic pruning; B: in MS, both resident microglia (green) and infiltrating peripheral monocytes (red) contact the nodes of Ranvier. Note that the processes of monocytes are found between the layers of myelin and the axon sheath, while the resident microglial processes are primarily in contact with adjacent monocytes and/or involved in debris clearance. Neuroinflammatory cells that have yet to be identified as either resident microglia or infiltrating monocytes (teal) that express TNF- $\alpha$, INOS, Nox2, and higher levels of activated calpain, wrap the axon initial segment. This wrapping is involved in a notable reduction in the length of the axon initial segment; C: following TBI, macrophages (monocytes and/or microglia) phagocytosis the Wallerian debris from the degenerating distal axonal segments of an injured axons. Potential hyperexcitability of neurons following TBI induces microglial process convergence onto the neuronal soma via elevated ATP levels and/or glutamate levels. Rod microglia (green) are also common along the apical dendrite following injury; however, their function is currently unknown. Microglial process convergence onto the proximal injured axonal segment is associated with P2Y12 and potentially confers neuroprotective effects on the damaged axon leading to axonal sprouting. CNS: central nervous system; MS: multiple sclerosis; TBI: traumatic brain injury; TNF: tumor necrosis factor; CSF1: colony stimulating factor 1; INOS: inducible nitric oxide synthase; Nox2: NADPH oxidase 2

strongly suggesting that microglia play a role in regulating AIS structure and function ${ }^{[45]}$. Additionally, when repeated stimulations were used to induce neuronal hyperexcitability, microglia extended their processes and wrapped around axons ${ }^{[35]}$. This induced a rapid repolarization in the neuron back to resting levels which was lost when microglia were pharmacologically blocked ${ }^{[35]}$.

Neuroinflammatory microglial changes are associated with various pathologies, including, but not limited to, spinal cord injury, neurodegenerative diseases, and early-life stress ${ }^{[46-49]}$. Alterations in the form and frequency of physical microglial-axonal contacts, however, have been described in the most detail in multiple sclerosis (MS) and traumatic brain injury (TBI), therefore this review focuses on these two disease states $^{[45,50-52]}$. Many of the changes in microglial-neuronal contacts appear to be dependent on the disease state, in which there are alterations in microglial associations with specific axonal segments. Below, we review the interactions of microglial processes with axonal segments, focusing on their associations with various axonal domains and the unique alterations of these physical interactions in MS and TBI. 


\section{NEUROINFLAMMATION IN MS}

MS is an autoimmune-mediated disease of the CNS that is characterized by inflammation and demyelination. While the cause of MS is not fully understood, it is accepted that neuroinflammation, resulting from the accumulation and activation of macrophages (derived from microglia or infiltrating monocytes) in the human CNS, is a crucial step in MS pathogenesis, which culminates in injury to myelin and axons and disrupts the flow of information ${ }^{[53-56]}$. The autoimmune nature of MS and the role of autoreactive peripheral $\mathrm{T}$ cells is highly complex and has been reviewed previously ${ }^{[57]}$. Therefore, we do not discuss the autoreactive peripheral immune cells in this review. Furthermore, destruction of myelin and axons, as well as oligodendrocyte cell-death, are directly related to the numbers of activated inflammatory cells ${ }^{[3,58-60]}$. The symptoms of MS range widely based on the CNS region affected and include a variety of motor or sensory dysfunctions such as muscle weakness, spasticity, tremor, unexplained pain or numbness, vision problems, and cognitive deficits ${ }^{[6]]}$. While demyelination is a hallmark of MS, axonal injury is also a prominent pathological feature and is a major contributor of chronic disability in patients ${ }^{[59,60,62-64]}$. The types of axonal injuries in MS and its models include the formation of axonal swellings, reduced levels of $\mathrm{Na}^{+} / \mathrm{K}^{+}$ ATPase, synaptic damage, axon transection, and disruption of axonal domains, such as the node of Ranvier (NOR) and the AIS ${ }^{[65-69]}$. These axonal injuries may occur as either a consequence of demyelination ${ }^{[65,70]}$ or as a primary event, independent of myelin loss ${ }^{[27,71]}$, although the mechanisms driving primary axonal pathology are not fully understood. It is appreciated that soluble factors produced by resident microglia and infiltrating monocytes and their interactions with peripheral immune cells play a pivotal role in driving axonal injury ${ }^{[59,60,72-75]}$; however, recent studies have implicated a mechanistic role for microglia/monocytes through physical interactions with axonal domains ${ }^{[6,27,28]}$.

Studies investigating axonal contact by microglia and/or infiltrating monocytes have utilized two common models of MS: a toxin-induced demyelinating model, cuprizone ${ }^{[27]}$, and an immune-mediated model, experimental autoimmune/allergic encephalomyelitis $(\mathrm{EAE})^{[6,27]}$. In the cuprizone model, a copperchelating toxin, cuprizone, is administered through chow resulting in oligodendrocyte cell death and, consequently, loss of myelin ${ }^{[75]}$. Demyelination is detectable 1-2 weeks after cuprizone treatment with peak demyelination occurring by 5-6 weeks of exposure ${ }^{[76-78]}$. The cuprizone model yields substantial demyelination and, upon removal of toxin-containing chow, spontaneous remyelination occurs. While this model does not recapitulate immune-mediated aspects of MS, it does allow for the investigation of fundamental mechanistic questions of the demyelination/remyelination process and roles of myelin in the stability of axonal domains ${ }^{[75]}$. The EAE model is an immune-mediated model that is induced through subcutaneous injection of myelin proteins accompanied by pertussis toxin and an adjuvant to ignite an inflammatory response ${ }^{[75,79,80]}$. The resulting neuroinflammation recapitulates key pathological features of MS such as inflammation, demyelination, and neuronal insults ${ }^{[75,80,81]}$. These two models allow for the rigorous assessment of MS-associated alterations in microglial-axonal interaction due to demyelination both in the presence of and independent from the autoreactive inflammatory response.

\section{MICROGLIAL CONTACT WITH THE NOR IN MODELS OF MS}

Axonal function requires maintenance of the $\mathrm{NOR}^{[82]}$, and a major regulator of nodal axonal domain stability is myelin integrity ${ }^{[77,83-89]}$. For example, cuprizone-induced demyelination resulted in loss of nodal and paranodal clustered proteins ${ }^{[77]}$. Other studies have also demonstrated loss of nodal protein clustering as a downstream consequence of demyelination in mouse models of MS and postmortem MS tissue ${ }^{[67,69,90,91]}$. In addition to NOR disruption, analyses of human MS tissues have revealed that prominent microglia/ macrophage accumulation correlates with active demyelination ${ }^{[56,59,60,67]}$. Indeed, myelin is required for NOR stability; however, NOR protein clustering can also be disrupted independent of demyelination. Howell et al. ${ }^{[6]}$ used immunohistochemical techniques to study NOR integrity in normal-appearing white matter of MS cases and in EAE and found NOR disruption correlated with local microglial inflammation but was independent of demyelinating lesions and did not correlate with the density of infiltrating lymphocytes. This was 
consistent with other studies demonstrating that numbers of microglia/macrophages correlate to EAE severity ${ }^{[27,72-74]}$. However, the cellular mechanisms by which microglia/infiltrating macrophages promote disease progression and whether these cells play differential roles in initiating demyelination or promoting repair remain unknown ${ }^{[61,92,93]}$. Yamasaki et al. ${ }^{[6]}$ began to elucidate the roles these cell types play in the disease course of EAE and their differential roles in myelin disruption. Serial block-face scanning electron microscopy of mice, in which the resident microglia fluoresced green and the infiltrating monocyte-derived macrophages fluoresced red, was utilized to distinguish the two inflammatory cell populations and to investigate their role in demyelination ${ }^{[6]}$. It was demonstrated that both microglia and infiltrating peripheral monocyte-derived macrophages contact the axo-glial unit at the NOR in the spinal cord of EAE-induced mice at disease onset [Figure $1 \mathrm{~B}]^{[6]}$. They found that most $(73 \%)$ of the NOR investigated (both intact and disrupted) were physically contacted by some sort of macrophage ${ }^{[6]}$. Interestingly, microglial association with the axo-glial unit was limited, while monocyte-derived infiltrating macrophage contact at the NOR was more extensive ${ }^{[6]}$. Monocyte-derived macrophage processes were found extended between the myelin and axolemma, potentially uprooting paranodal contacts and initiating demyelination [Figure $1 \mathrm{~B}]^{[6]}$. In contrast, microglial processes contacted the axo-glial unit at the NOR, but the microglial processes did not extend beneath the axolemma and, instead, appeared to primarily interact with adjacent macrophages and appeared to be involved in debris clearance [Figure 1B] ${ }^{[6]}$. Gene expression profiles supported that infiltrating monocyte-derived macrophages were highly phagocytic and pro-inflammatory, whereas microglia demonstrated a suppressed cellular metabolism and activation phenotype ${ }^{[6]}$. These findings suggest that, at disease onset, infiltrating macrophages initiate active demyelination while microglia perform myelin debris clearance, a function that supports tissue regeneration and affects the maturation of oligodendrocyte progenitor cells ${ }^{[3]}$.

The differential mechanisms underlying microglial contact at the NOR is still to be fully determined. It was shown that $\mathrm{C}-\mathrm{C}$ chemokine receptor type 2 (CCR2), a chemokine receptor essential for monocyte recruitment to CNS tissues during immune-mediated inflammation ${ }^{[94,95]}$, was important for recognition of disrupted NOR by infiltrating monocyte-derived macrophages ${ }^{[6]}$. Mice lacking CCR2 demonstrated reduced NOR contact by monocyte-derived macrophages and significantly less demyelination at EAE onset. Interestingly, CCR2-deficient mice displayed similar nodal pathology during the pre-onset stage of EAE (post-EAE induction but prior to onset of motor clinical symptoms), suggesting that inflammatory nodal disruption could be reversible if monocyte-derived macrophages were prevented from initiating demyelination at those $\operatorname{sites}^{[6]}$.

\section{MICROGLIAL CONTACT WITH THE AIS}

Microglia contact the AIS during normal development and throughout life, indicating that these cells likely play a role in the regulation of AIS structure and/or function in both the developing and mature CNS $[\text { Figure } 1 \mathrm{~A}]^{[45]}$. A recent study utilizing both EAE and cuprizone models of MS to assess MS-related axonal injury and their underlying mechanisms found that inflammatory microglia and/or Macrophages physically contact the $\mathrm{AIS}^{[27]}$. It was found that the AIS is a primary target in disease pathogenesis of $\mathrm{EAE}^{[27]}$. In this study, mice were induced with either myelin-oligodendrocyte glycoprotein + EAE or cuprizone and AIS integrity of cortical neurons was assessed using immunohistochemical techniques. The integrity of the AIS was assessed by immunolabeling for ankyrinG (AnkG), a protein critical for AIS establishment and maintenance ${ }^{[96-98]}$. Upon EAE induction, it was found that the number and length of AISs were significantly reduced and that the number of disrupted AISs was associated with disease severity and progression ${ }^{[27]}$. This loss of AIS integrity, however, was not associated with demyelination, neuronal death, or axonal damage, rather appeared to be mediated by inflammatory factors ${ }^{[27-29]}$. Specifically, AIS disruption was preceded by microglial morphological changes suggestive of enhanced reactivity and increased contact by Iba-1 positive inflammatory cells but occurred independently of demyelination ${ }^{[27]}$. The nature of microglial interaction with the AIS changed substantially following EAE, transitioning from microglial process 
alignment along the AIS and periodic process ends contacting the AIS [Figure 1A] to microglial processes completely wrapping around the AIS [Figure $1 \mathrm{~B}]^{[27,99]}$. Treatment with anti-inflammatory Didox, a freeradical scavenger and NF- $\mathrm{KB}$ modulator ${ }^{[100-102]}$, resulted in enhanced AIS structural integrity and reduction in microglial-AIS contact, indicating that EAE-induced inflammation is the driver for AIS disruption and enhanced microglial-AIS contact.

Microglial-AIS contact increased prior to and concomitant with changes in AIS structure, although it does not appear that contact alone drives AIS disruption. In the cuprizone model, demyelination and inflammation are present in the cortex; however, AISs were spared, suggesting the AIS, unlike the NOR, is not maintained by myelin presence ${ }^{[27,103]}$. Interestingly, in the cortex of cuprizone-fed mice, reactive microglia also enhanced contact with AISs but AIS structure was preserved ${ }^{[27]}$. Thus, the consequence of microglial-AIS contact appears to be stimulus dependent. In other models, microglia are recruited to and make contact with the initial portion of the axon and soma of hyperexcitable cells ${ }^{[35,36]}$. Microglial-axonal contact is activity dependent and results in a protective phenotype, preventing the neuron from excitotoxic death ${ }^{[35,36]}$. While live-imaging and physiological experiments have not been performed in MS models, analysis of AIS plasticity in EAE revealed structural changes of the AIS, such as decreased length ${ }^{[27]}$, which can occur in response to hyperexcitable environments ${ }^{[104-106]}$. Thus, the nature of microglial-AIS contacts may be context dependent and could either drive disruption or confer protection. Since the AIS is the axonal domain where action potentials are generated, this consistent microglial-AIS contact in both health and disease strongly implicates microglia as a regulator and/or modulator of neuronal function and further studies are needed to investigate the role of enhanced microglial interactions with the AIS in MS and its models.

The mechanisms mediating microglial contact with either the NOR or AIS remain undefined; however, as the molecular architecture is highly conserved between these two axonal segments, it is likely that the molecular mechanisms involved in associations with either region are similar. The fractalkine receptor CX3CR1 mediates microglial synaptic pruning and microglial contact with neuronal somatic-dendritic domains, and was, therefore, a prime candidate for mediating microglial-AIS contact ${ }^{[107-109]}$. However, absence of CX3CR1 fractalkine receptors on microglia did not alter contact with the AIS in the healthy mouse brain, suggesting that microglial-AIS interactions are not mediated through the fractalkine receptor $^{[45]}$. Loss of brevican and versican, specialized extracellular matrix molecules surrounding the AIS, also did not alter microglial contacts onto the AIS ${ }^{[45]}$. In an effort to determine if AIS proteins are necessary for microglial contact, the AIS master scaffolding protein AnkG was knocked down, which disrupted AIS protein clustering and significantly reduced the number of microglial-AIS contacts, suggesting that molecules normally restricted to the AIS are important for microglial-AIS contact ${ }^{[45]}$. Thus, some progress has been made in eliminating candidates that mediate microglial-AIS contact and in determining that an intact AIS is important for microglial contact, but these experiments ${ }^{[45]}$ focused on microglial contact specifically with the AIS.

\section{NEUROINFLAMMATION IN TBI}

TBI affects millions of people and is associated with devastating financial and societal costs linked to the long-term morbidities that develop and persist for years after the initial insult ${ }^{\left[10^{-113]}\right.}$. Recent studies have demonstrated the impact of inflammatory cascades in regulating many of these TBI-mediated outcomes $^{[114-118]}$. While astrocytes and infiltrating peripheral monocytes/macrophages do play a role in TBI-induced neuroinflammation, microglia are thought to be the critical mediators of these TBIinduced neuroinflammatory processes and, therefore, have been the primary focus of TBI-related neuroinflammatory investigations. However, as it is difficult to specifically identify resident microglia from peripheral infiltrating monocytes following TBI, many studies call both populations "microglia" for simplicity. In the following sections, we do the same unless the population is specifically known to be infiltrating monocytic in origin. 
Studies have also demonstrated neuroinflammation in various brain regions within the human population following $\mathrm{TBI}^{[119-122]}$. Molecular imaging studies have demonstrated microglial activation in populations of TBI patients as visualized via positron emission tomography using ligands for the mitochondrial translocator protein, TSPO, following brain injury ${ }^{[114,119-121]}$. While the TSPO ligands used in these studies have been shown to significantly increase binding to activated microglia post-TBI, they also bind to other neuroinflammatory cells following trauma ${ }^{[114,119-121]}$. Complementary histopathological studies investigating the extent and localization of various neuroinflammatory makers, including microglial CD68 and/or complement receptors, as well as morphological indications of microglial activation also demonstrated significant inflammation following brain injury in humans ${ }^{[123-125]}$. Many of these studies also indicate that neuroinflammation persists and evolves years after the initial head injury and that inflammation may become more severe with time post-injury ${ }^{[117,121,125,126]}$.

The majority of preclinical TBI models can be divided into focal and diffuse injury models, with some of the most used models being the controlled cortical impact (focal), central fluid percussion injury (diffuse), lateral fluid percussion injury (mixed focal and diffuse), and head rotational (diffuse) models; however, the specific models used to induce TBI are highly varied. For a review of the different types of TBI preclinical models, please see ${ }^{[127,128]}$. While the occurrence of microglial activation following TBI is rather well accepted, the role of activated microglia in the post-injury brain is far more enigmatic. A wide range of studies using various rodent models of brain injury have demonstrated that activated microglia can have a host of functions. For simplicity's sake, these functions were lumped into two historical categories: M1, or pro-inflammatory microglia, that were involved with cytokine release that lead primarily to neuronal damage and $\mathrm{M} 2$, or anti-inflammatory microglia, that were associated with release of neurotrophic factors and cytokines downregulating the inflammatory responses ${ }^{[129-132]}$. These binary definitions, however, appear too simplistic for the complex interactions between the pro- and anti-inflammatory signals coming from activated microglia following $\mathrm{TBI}^{[133]}$. While the nomenclature for microglia falling along the inflammatory spectrum is still up for debate, studies do indicate that location, time following TBI, and systemic factors, including stress and infection, can push activated microglia toward a more pro-inflammatory state $^{[131,132,134,135]}$. Information regarding these microglial populations is covered in greater detail in the following reviews ${ }^{[129,133,134]}$.

Many well-designed studies using rodents have indicated that reduction of activated microglial and/ or targeting various neuroinflammatory signaling pathways ameliorates downstream pathology and behavioral morbidity ${ }^{[136-149]}$. One of the most common compounds used to assess the role of microglial activation following TBI is the second generation tetracycline drug, minocycline ${ }^{[129]}$. Minocycline is traditionally used clinically as an antibiotic; however, it has various other uses/effects including as a powerful anti-inflammatory compound ${ }^{[140]}$. Various studies demonstrate significant reductions in damaged or dying neurons, reduced lesion volumes, enhanced behavioral scores, and drastic reduction in proinflammatory cytokine expression following administration of minocycline, indicating that interactions between activated microglia and neurons could precipitate neurodegeneration ${ }^{[141-143]}$. In fact, minocycline is currently being assessed for safety in clinical trials for the treatment of TBI-associated morbidities thought to be regulated by inflammation ${ }^{[144]}$. However, other studies indicate that prolonged microglial inhibition via minocycline administration precipitates enhanced neurodegeneration and inflammation or no effect at all, demonstrating the complexity of neuroinflammatory responses following $\mathrm{TBI}^{[145-147]}$. Based on the fact that minocycline has a multitude of effects, it is also possible that the variability in these studies' findings highlight the potential that non-inflammatory minocycline-induced reductions in TBI-mediated pathology in turn reduce inflammation and microglial activation ${ }^{[140,147,148]}$. In support of this possibility are studies showing little or no effect of genetic microglial elimination or direct microglial inhibition using compounds targeting the CSF1 receptor in altering TBI-induced pathology ${ }^{[135,149,150]}$. Additionally, administration of pro-inflammatory stimuli into the ventricle, surpassing induction of peripheral inflammatory responses, 
does not result in enhanced post-injury neurodegeneration, indicating that the peripheral inflammatory response, more than direct microglial activation, precipitates proinflammation-mediated secondary insults ${ }^{[134,151]}$. Overall, these studies underscore the intricacies of TBI-induced microglial activation and our limited understanding of microglial-neuronal interactions following brain injury.

\section{PHAGOCYTOSIS FOLLOWING TBI}

One of the most well-studied physical interactions between microglia and neuronal segments following TBI is phagocytic engulfment. As in the non-injured brain, activated microglia serve a prominent and vital role in the clearance of cellular debris following brain injury. Upon the initial TBI insult, a multitude of cellular pathologies progress. One of the most well studied pathologies, and the hallmark of diffuse brain injury following TBI, is diffuse axonal injury/traumatic axonal injury ${ }^{[125,152-156]}$. Axonal injury first manifests as disruption of molecular transport anterogradely down the axon and progresses over hours, days, and months following injury to a disconnection at the point of initial transport disruption, resulting in a proximal axonal segment that remains connected to the neuronal cell body and a distal axonal segment that undergoes Wallerian degeneration ${ }^{[157-159]}$. Phagocytosis by activated microglia is required to engulf and clear away the axonal and myelin debris from the Wallerian degeneration of the distal axonal segment and involves the toll-like receptors, TREM-2, complement receptors 3 and 4, as well as MAC-2, for the engulfment of myelin, and the purinergic receptor P2RY6 [Figure $1 \mathrm{C}]^{[160,161]}$. Ultrastructural assessments of the injured brain have demonstrated significant phagocytosis of Wallerian debris by activated microglia following $\mathrm{TBI}^{[52,166,162]}$. Microglia with ameboid morphologies, indicative of phagocytic activity, were found primarily in proximity to the distal axonal segment sustaining dieback, but not the proximal axonal segments, following TBI-induced optic nerve damage ${ }^{[163]}$. Further, expression of mRNA indicative of phagocytic activity is significantly increased following trauma ${ }^{[150]}$. It should be noted, however, that both microglia and astrocytes containing phagocytic material have been observed, demonstrating that, while microglia may be the primary phagocytic cells in the brain, astrocytes also phagocytosis debris following injury ${ }^{[162]}$. Additionally, not all activated microglia were observed to be phagocytic following TBI, indicating that phagocytosis is not the only microglial-axonal interaction upregulated following $\mathrm{TBI}^{[116]}$.

\section{ROD MICROGLIA AND TBI}

The readily identifiable, yet mysterious, "rod microglia" have been noted following TBI in a variety of preclinical models and in the human population. This subset of microglia appear following injury and are defined exclusively by their rod-like morphology and chain-like associations that form long microglial trains of several rod microglia lined up end-to-end [Figure $1 \mathrm{C}]^{[164]}$. These rod-shaped microglia have been described following a variety of neurological diseases, including neurosyphilis, and appear to be both nonphagocytic and reversible ${ }^{[165]}$. Both rod microglia and microglial trains appear primarily in brain regions in which the fiber tracks are linear, such as the neocortex, brainstem, and hippocampus ${ }^{[124,166-168]}$. This subset of rod microglia, however, appear to be absent in areas that are not linearly arranged, such as the thalamus ${ }^{[166]}$. The formation of microglial trains appears to be associated with p38; however the function of these microglial trains remains unknown ${ }^{[169]}$. Recently, it was found that microglial trains formed by rod microglia align with the apical dendrite, but not the axon as was previously thought, of pyramidal neurons in the rodent cortex [Figure $1 \mathrm{C}$ ] and spatially associate with astrocytes, indicating that this subset of microglial-neuronal interaction is neuronal-segment specific and could be involved in an additional interplay between neuroinflammatory cell types ${ }^{[150]}$. However, the study of rod microglia following TBI is still in its infancy and requires further investigation into the timing and function of this microglial-axonal interaction subtype.

\section{TBI-INDUCED PROCESS CONVERGING AND DIVERGING MICROGLIA}

Over the last several years, another subtype of microglial-neuronal interaction has been observed following brain injury. This interaction subtype manifests as physical contacts between activated microglia and 

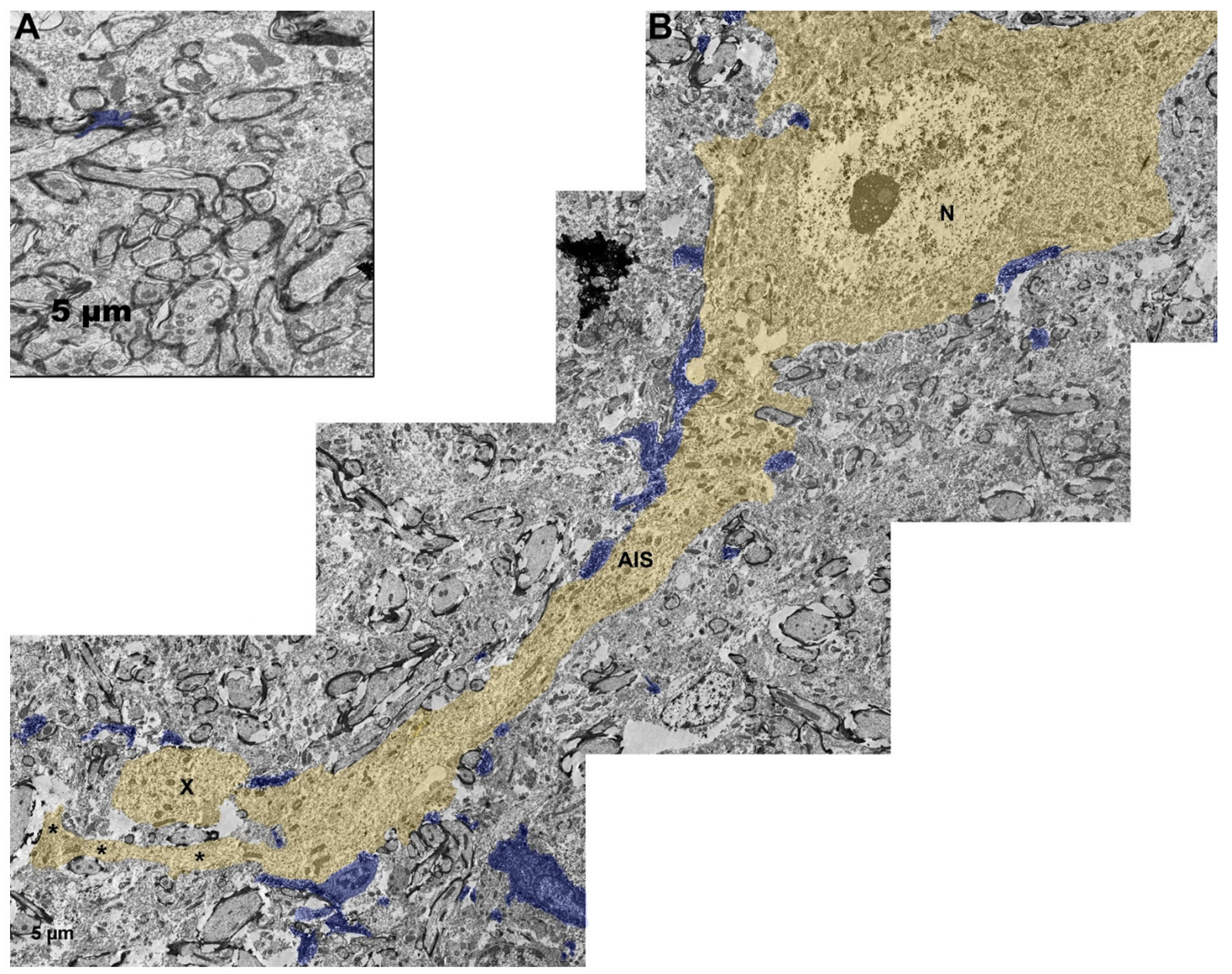

Figure 2. Ultrastructure of microglial process contacts onto axonal segments following TBI. Electron micrographs of Iba-1 immuno-labeled microglia contacting: A: intact non-injured axons in sham-injured micro pig thalamus; B: injured axonal segment in the thalamus of micro pigs acutely (one day) following diffuse TBI. Iba-1-labeled microglial processes are pseudo-colored blue and the injured axon is pseudocolored yellow for clarity. While few microglial processes were observed in direct contact with axons normally, microglial processes were observed in direct contact various segments of the neuron, including the soma ( $N=$ nucleus), AIS, and the proximal axonal swelling $(X)$ of the injured neuron. Note that the proximal axonal segment of the injured neuron demonstrates ultrastructural characteristics of axonal sprouting $\left(^{*}\right)$. Scale bar: $5 \mu \mathrm{m}$. AIS: axon initial segment; TBI: traumatic brain injury

the proximal axonal segment of injured axons following $\mathrm{TBI}^{[51]}$. Using a micro pig model of central fluid percussion-generated diffuse TBI, paired with multiplexed immunohistochemical quantitative image analysis, recent studies found processes from activated microglia converge onto adjacent injured thalamic axons acutely (hours to one day post-injury) following injury, a phenomenon termed "microglial process convergence" (MPC; Figure $1 \mathrm{C})^{[50,52]}$. These process converging (PC) microglia were neither ameboid nor rod shaped, rather they displayed shortened processes, with fewer process branches, morphological changes indicative of activation without progression to phagocytosis ${ }^{[1,51,52]}$. Ultrastructural assessments confirmed that PC microglia were non-phagocytic in nature ${ }^{[50,52]}$. Additionally, a single injured axon could have processes converging from multiple PC microglia ${ }^{[50,52]}$. As the majority of diffuse axonal injury following TBI appears to occur in or adjacent to the AIS, it is likely that the proximal axonal swellings in which this subtype of PC microglia are converging are nearer to the AIS than to more distal points along the axon [Figure 2$]^{[170,171]}$. Another group using a micro pig model of head-rotation-induced diffuse TBI found indications of potential PC microglia associated with injured neurons following brain injury ${ }^{[172]}$. Specifically, also using multiplexed immunohistochemical quantitative image analysis, they observed that microglia were in closer proximity to injured neuronal soma in multiple brain regions following TBI compared to 
neurons in sham injured micro pigs [Figure $1 \mathrm{C}]^{[172]}$. These PC microglia also appeared activated without falling into the morphological categories of phagocytic or rod microglia ${ }^{[172]}$. Another recent study found that MPC onto cell bodies of injured neurons is associated with protection. Specifically inhibition of this MPC increased ischemia-induced lesion volume, behavioral morbidity, and calcium influx ${ }^{[37]}$. Additionally, ischemic injury results in microglial process contacts with injured synapses that are nearly 10 times longer in duration than the 4-5-min-long contacts observed in non-injured animals using a thinned-skull live imaging approach ${ }^{[9]}$. Therefore, it is likely that MPC could involve an increase in both the number of microglial processes as well as the duration of these contacts onto injured axons.

The mechanisms involved in regulating MPC onto neuronal and axonal segments has primarily been studied in mouse models of epilepsy. The number of microglial process contacts appear to be directly related to the level of neuronal activity, in that MPC was significantly reduced upon reduction in neuronal activity via either temperature reduction or tetrodotoxin administration in thinned-skull live-imaging studies $^{[9]}$. Induction of neuronal hyperexcitability to the point of excitotoxicity also promoted MPC ${ }^{[173]}$. Hyperexcitability-induced MPC resulted in reduced neuronal activity and overall increased neuronal survival in the face of otherwise excitotoxic events that were not seen following microglia elimination or inhibition of MPC ${ }^{[173,174]}$. Neuronal excitation precipitates higher extracellular and lower intracellular $\mathrm{Ca}^{2+}$ concentrations and increased extracellular ATP concentrations around the active neuron, which appear to be primary molecular mediators of hyperexcitability-induced $\mathrm{MPC}^{[173-176]}$. ATP-mediated MPC was found to promote polarization of microglial process outgrowth toward the location with high ATP levels [Figure $1 \mathrm{C}]^{[177]}$. Elimination of the purinergic receptor $\mathrm{P}_{2} \mathrm{Y} 12$ or the fractalkine receptor CX3CR1 drastically reduced MPC onto hyper-excitable neurons, indicating that microglial $\mathrm{P}_{2} \mathrm{Y}_{12}$ and $\mathrm{CX} 3 \mathrm{CR} 1$ are required for ATP-mediated $\mathrm{MPC}^{[176,178]}$. Excitatory neurons also release glutamate upon excitation. Concentration of extracellular glutamate has also been found to mediate hyperexcitability-induced MPC potentially via activation of N-methyl-D-aspartate (NMDA) receptors ${ }^{[174,178]}$. Glutamate/NMDA-mediated MPC was also found to require microglial $\mathrm{P}_{2} \mathrm{Y} 12$, but not $\mathrm{CX}_{3} \mathrm{CR}_{1} 1^{[177]}$. Glutamate-mediated MPC also promoted nonpolarized outgrowth of microglial processes, indicating that different molecular mechanisms of hyperexcitability-induced MPC may result in different forms of MPC [Figure $1 \mathrm{C}]^{[177]}$. Further, these mechanisms appear distinct from those involved in microglial phagocytosis, as knocking out or inhibiting P2Y12 or NMDA inhibited MPC without affecting phagocytosis ${ }^{[178]}$. While epilepsy and TBI are different CNS diseases with distinct neuropathologies, the molecules and mechanisms discussed above are prime candidates for regulation of TBI-induced MPC. In fact, the Jacobs group found that both axotomized and intact neurons demonstrate hyperexcitability one day following TBI in mice that appears to resolve in the axotomized population, but not the intact neurons, by two days post-injury ${ }^{[179,180]}$. While TBI-induced MPC onto the proximal axonal segments of axotomized neurons has yet to be thoroughly investigated, these findings indicate the potential that similar mechanisms might be at play in TBI and epilepsy-induced MPC.

It appears that TBI-induced MPC may be species dependent, as it was found that rats sustaining the same central fluid percussion injury paradigm as their pig counterparts did not demonstrate $\mathrm{MPC}^{[50]}$. Rather, at the same time points following injury, there was a significant decrease in microglial contacts onto injured proximal axonal segments in the rats, indicating microglial processes that diverged from injured axons or microglia process divergence $(\mathrm{MPD})^{[50]}$. This MPD observed in rats is in alignment with previous observations in injured rats and mice that activated microglia do not physically associate with proximal segments of injured axons following brain injury ${ }^{[116,163]}$. TBI-associated MPD was also observed by a group assessing the occurrence of microglia associations with the AIS, regardless of axonal injury, following TBI in mice ${ }^{[45]}$. They demonstrated that microglial contacts onto the AIS of axons significantly decreased following TBI in mice, indicating MPD similar to that observed by the other groups following TBI in rodents ${ }^{[45,50,116,163]}$. In contrast to those studies, however, these AIS-associating, or "AXIS", microglia were not specific to injured axonal segments and appeared ramified (morphologically not activated), indicating that 
these AXIS microglia could represent a distinct subtype of MPD microglia ${ }^{[45,50]}$. The interaction between the AXIS microglia and the AIS appears to be ankrin-G and GABA mediated, while the fractalkine receptor, CX3CR1, does not appear necessary for the AXIS microglial interactions ${ }^{[45]}$.

There are reports indicating that microglia physically interact with injured axons following TBI in the human brain. In 2014, a study demonstrated co-labeling of microglia with injured proximal axonal swellings in brains of veterans who had histories of blast injury exposure ${ }^{[181]}$. Another study showed potential PC microglia contacting injured axonal swellings when employing double-labeling techniques in human TBI tissue ${ }^{[182]}$. These studies indicate that microglial processes may contact axonal swellings in the human brain following TBI; however, further investigation is needed to comprehensively assess potential alterations in microglial-neuronal physical interactions in the human population and address how those changes compare to those observed pre-clinically.

Additionally, a study investigating the expression of neuronal outgrowth marker, GAP43, in injured axonal segments as it related to the density of microglia in brain tissue from people diagnosed with MS or TBI demonstrated a positive correlation between neuronal regeneration and microglial density following TBI in clinical samples [Figure $1 \mathrm{C}]^{[183]}$. Other studies have also observed GAP43 expression in proximal axonal swellings following injury in both human tissue and following induction of TBI in pre-clinical models ${ }^{[184-186]}$. Ultrastructural assessments further demonstrated morphological alterations indicative of active axonal sprouting of proximal axonal swellings following TBI, demonstrating that axonal process outgrowth following TBI is possible and potentially likely [Figure 2] ${ }^{[184,185]}$. Microglia have been shown to express neurotrophic factors, such as nerve growth factor, following TBI, supporting a potential role for MPC in post-injury axonal outgrowth ${ }^{[187]}$. Microglia may also release exosomes that induce neurite outgrowth $^{[19]}$. The role of MPC and/or MPD in potential post-injury axonal sprouting, however, remains speculative.

\section{CONCLUSION}

It is well accepted that microglia mediate neuroinflammatory processes in health and disease via proand anti-inflammatory cytokines and chemokines. However, microglia also appear to mediate neuronal function through physical contacts onto various neuronal segments, including dendrites, synapses, cells bodies, and axons. While the study of microglial-axonal contacts is still in its infancy, there are indications that these contacts play diverse and important roles during normal development and in the healthy CNS as well as following TBI or in disease states, such as MS. Analysis of microglia in experimental and human tissues demonstrate that microglia exhibit a spectrum of morphologies including ramified, rodlike, hypertrophied, and ameboid that all exert unique contact subtypes onto axonal segments indicative of the diverse roles microglial-axonal interactions play. Microglia and infiltrating monocytes contact various axonal segments in unique and specific ways that appear tied to the axonal region contacted, the morphology of the microglia, and the disease state. Further, it appears that the presence of microglia contacts at axonal domains may confer protection. Some of the immediate questions for this burgeoning field focus on the potential ameliorative effects of microglial contacts onto axonal and other neuronal segments as well as the timing of these interactions following various pathologies. Future examinations of axonal interactions using functional assessments and live imaging techniques could refine the distinction between axonal contacts of resident microglia and those formed by peripheral monocyte-derived infiltrating macrophages and help elucidate the nature of these interactions. Furthermore, identifying the molecules mediating contact between microglia and the axon will point toward new strategies to treat disease and promote repair in diverse inflammatory pathologies. The studies reviewed herein underscore the importance of microglial-axonal contacts in the regulation of neural signaling and the need for further investigation into these variable interactions in both the healthy and injured CNS. 


\section{DECLARATIONS}

\section{Authors' contributions}

Conceptualized and wrote this review: Benusa SD, Lafrenaye AD

\section{Availability of data and materials}

Not applicable.

\section{Financial support and sponsorship}

Lafrenaye AD is supported by a grant from the National Institute of Neurological Disorders and Stroke (NINDS) (Ro1NS0961430).

\section{Conflicts of interest}

All authors declared that there are no conflicts of interest.

\section{Ethical approval and consent to participate}

Not applicable.

\section{Consent for publication}

Not applicable.

\section{Copyright}

(C) The Author(s) 2020.

\section{REFERENCES}

1. Ginhoux F, Greter M, Leboeuf M, Nandi S, See P, et al. Fate mapping analysis reveals that adult microglia derive from primitive macrophages. Science 2010;330;841-5.

2. Schulz C, Gomez Perdiguero E, Chorro L, Szabo-Rogers H, Cagnard N, et al. A lineage of myeloid cells independent of Myb and hematopoietic stem cells. Science 2012;336:86-90.

3. Wolf SA, Boddeke HW, Kettenmann H. Microglia in Physiology and Disease. Annu Rev Physiol 2017;79:619-43.

4. Bennett ML, Bennett FC. The influence of environment and origin on brain resident macrophages and implications for therapy. Nat Neurosci 2020;23:157-66.

5. Prinz M, Priller J. The role of peripheral immune cells in the CNS in steady state and disease. Nat Neurosci 2017;20:136-44.

6. Yamasaki R, Lu H, Butovsky O, Ohno N, Rietsch AM, et al. Differential roles of microglia and monocytes in the inflamed central nervous system. J Exp Med 2014;211:1533-49.

7. Nimmerjahn A, Kirchhoff F, Helmchen F. Resting microglial cells are highly dynamic surveillants of brain parenchyma in vivo. Science 2005;308:1314-8.

8. Sierra A, Tremblay MÈ, Wake H. Never-resting microglia: physiological roles in the healthy brain and pathological implications. Front Cell Neurosci 2014;8:240.

9. Wake H, Moorhouse AJ, Jinno S, Kohsaka S, Nabekura J. Resting microglia directly monitor the functional state of synapses in vivo and determine the fate of ischemic terminals. J Neurosci 2009;29:3974-80.

10. Davalos D, Grutzendler J, Yang G, Kim JV, Zuo Y, et al. ATP mediates rapid microglial response to local brain injury in vivo. Nat Neurosci 2005;8:752-8.

11. von Bernhardi R, Heredia F, Salgado N, Muñoz P. Microglia function in the normal brain. Adv Exp Med Biol 2016;949:67-92.

12. Kettenmann H, Hanisch UK, Noda M, Verkhratsky A. Physiology of microglia. Physiol Rev 2011;91:461-553.

13. Byrnes KR, Loane DJ, Stoica BA, Zhang J, Faden AI. Delayed mGluR5 activation limits neuroinflammation and neurodegeneration after traumatic brain injury. J Neuroinflammation 2012;9:43.

14. Tay TL, Mai D, Dautzenberg J, Fernández-Klett F, Lin G, et al. A new fate mapping system reveals context-dependent random or clonal expansion of microglia. Nat Neurosci 2017;20:793-803.

15. Crotti A, Ransohoff RM. Microglial physiology and pathophysiology: insights from genome-wide transcriptional profiling. Immunity 2016;44:505-15.

16. Chen SH, Oyarzabal EA, Hong JS. Critical role of the Mac1/NOX2 pathway in mediating reactive microgliosis-generated chronic neuroinflammation and progressive neurodegeneration. Curr Opin Pharmacol 2016;26:54-60.

17. Ransohoff RM, Khoury JE. Microglia in health and disease. Cold Spring Harb 2016;8:a020560.

18. Chen Z, Trapp BD. Microglia and neuroprotection. J Neurochem 2016;136 Suppl 1:10-7.

19. Raffo-Romero A, Arab T, Al-Amri IS, Le Marrec-Croq F, Van Camp C, et al. Medicinal leech CNS as a model for exosome studies in 
the crosstalk between microglia and neurons. Int J Mol Sci 2018;19:4124.

20. Pósfai B, Cserép C, Orsolits B, Dénes Á. New insights into microglia-neuron interactions: a neuron's perspective. Neuroscience 2019;405:103-17.

21. Kumar A, Barrett JP, Alvarez-Croda DM, Stoica BA, Faden AI, et al. NOX2 drives M1-like microglial/macrophage activation and neurodegeneration following experimental traumatic brain injury. Brain Behav Immun 2016;58:291-309.

22. Hool LC. The L-type $\mathrm{Ca}(2+)$ channel as a potential mediator of pathology during alterations in cellular redox state. Heart Lung Circ 2009;18:3-10.

23. Hool LC, Arthur PG. Decreasing cellular hydrogen peroxide with catalase mimics the effects of hypoxia on the sensitivity of the L-type Ca2+ channel to $\beta$-adrenergic receptor stimulation in cardiac myocytes. Circ Res 2002;91:601-9.

24. Hudasek K, Brown ST, Fearon IM. H2O2 regulates recombinant $\mathrm{Ca} 2+$ channel $\alpha 1 \mathrm{C}$ subunits but does not mediate their sensitivity to acute hypoxia. Biochem Biophys Res Commun 2004;318:135-41.

25. Mossakowski AA, Pohlan J, Bremer D, Lindquist R, Millward JM, et al. Tracking CNS and systemic sources of oxidative stress during the course of chronic neuroinflammation. Acta Neuropathol 2015;130:799-814.

26. Benned-Jensen T, Christensen RK, Denti F, Perrier JF, Rasmussen HB, et al. Live imaging of Kv7.2/7.3 cell surface dynamics at the axon initial segment: high steady-state stability and calpain-dependent excitotoxic downregulation revealed. J Neurosci 2016;36:2261-6.

27. Clark KC, Josephson A, Benusa SD, Hartley RK, Baer M, et al. Compromised axon initial segment integrity in EAE is preceded by microglial reactivity and contact. Glia 2016;64:1190-1209.

28. Benusa SD, George NM, Sword BA, DeVries GH, Dupree JL. Acute neuroinflammation induces AIS structural plasticity in a NOX2dependent manner. J Neuroinflammation 2017;14:116.

29. Clark K, Sword BA, Dupree JL. Oxidative stress induces disruption of the axon initial segment. ASN Neuro 2017;9:1759091417745426.

30. Del Puerto A, Fronzaroli-Molinieres L, Perez-Alvarez MJ, Giraud P, Carlier E, et al. ATP-P2X7 receptor modulates axon initial segment composition and function in physiological conditions and brain injury. Cereb Cortex 2015;25:2282-94.

31. Evans MD, Sammons RP, Lebron S, Dumitrescu AS, Watkins TB, et al. Calcineurin signaling mediates activity-dependent relocation of the axon initial segment. J Neurosci 2013;33:6950-63.

32. Schafer DP, Jha S, Liu F, Akella T, McCullough LD, et al. Disruption of the axon initial segment cytoskeleton is a new mechanism for neuronal injury. J Neurosci 2009;29:13242-54.

33. Bilimoria PM, Stevens B. Microglia function during brain development: new insights from animal models. Brain Res 2015;1617:7-17.

34. Bordt EA, Ceasrine AM, Bilbo SD. Microglia and sexual differentiation of the developing brain: a focus on ontogeny and intrinsic factors. Glia 2019; Epub ahead of print. doi: 10.1002/glia.23753.

35. Kato G, Inada H, Wake H, Akiyoshi R, Miyamoto A, et al. Microglial contact prevents excess depolarization and rescues neurons from excitotoxicity. eNeuro 2016;3.

36. Li Y, Du XF, Liu CS, Wen ZL, Du JL. Reciprocal regulation between resting microglial dynamics and neuronal activity in vivo. Dev Cell 2012;23:1189-202.

37. Cserép C, Pósfai B, Lénárt N, Fekete R, László ZI, et al. Microglia monitor and protect neuronal function through specialized somatic purinergic junctions. Science 2020;367:528-37.

38. Miyamoto A, Wake H, Ishikawa AW, Eto K, Shibata K, et al. Microglia contact induces synapse formation in developing somatosensory cortex. Nat Commun 2016;7:12540.

39. Eyo UB, Murugan M, Wu LJ. Microglia-neuron communication in epilepsy. Glia 2017;65:5-18.

40. Eyo UB, Wu LJ. Bidirectional microglia-neuron communication in the healthy brain. Neural Plast 2013;2013:456857.

41. Kettenmann H, Kirchhoff F, Verkhratsky A. Microglia: new roles for the synaptic stripper. Neuron 2013;77:10-8.

42. Schafer DP, Lehrman EK, Kautzman AG, Koyama R, Mardinly AR, et al. Microglia sculpt postnatal neural circuits in an activity and complement-dependent manner. Neuron 2012;74:691-705.

43. Tremblay MÈ, Lowery RL, Majewska AK. Microglial interactions with synapses are modulated by visual experience. PLoS Biol 2010;8:e1000527.

44. Weinhard L, di Bartolomei G, Bolasco G, Machado P, Schieber NL, et al. Microglia remodel synapses by presynaptic trogocytosis and spine head filopodia induction. Nat Commun 2018;9:1228.

45. Baalman K, Marin MA, Ho TS, Godoy M, Cherian L, et al. Axon initial segment-associated microglia. J Neurosci 2015;35:2283-92.

46. Catale C, Gironda S, Iacono LL, Carola V. Microglial function in the effects of early-life stress on brain and behavioral development. J Clin Med 2020;9:E468.

47. Koellhoffer EC, McCullough LD, Ritzel RM. Old maids: aging and its impact on microglia function. Int J Mol Sci 2017;18:769.

48. Akhmetzyanova E, Kletenkov K, Mukhamedshina Y, Rizvanov A. Different approaches to modulation of microglia phenotypes after spinal cord injury. Front Syst Neurosci 2019;13:37

49. Gaudet AD, Fonken LK. Glial cells shape pathology and repair after spinal cord injury. Neurotherapeutics 2018;15:554-77.

50. Gorse KM, Lafrenaye AD. The importance of inter-species variation in traumatic brain injury-induced alterations of microglial-axonal interactions. Front Neurol 2018;9:778.

51. Lafrenaye AD. Physical interactions between activated microglia and injured axons: do all contacts lead to phagocytosis? Neural Regen Res 2016;11:538-40.

52. Lafrenaye AD, Todani M, Walker SA, Povlishock JT. Microglia processes associate with diffusely injured axons following mild traumatic brain injury in the micro pig. J Neuroinflammation 2015;12:186.

53. Bitsch A, Schuchardt J, Bunkowski S, Kuhlmann T, Brück W. Acute axonal injury in multiple sclerosis. Correlation with demyelination and inflammation. Brain 2000;123:1174-83.

54. Hemmer B, Kerschensteiner M, Korn T. Role of the innate and adaptive immune responses in the course of multiple sclerosis. Lancet Neurol 2015;14:406-19. 
55. Sørensen TL, Ransohoff RM. Etiology and pathogenesis of multiple sclerosis. Semin Neurol 1998;18:287-94.

56. Trebst C, Sørensen TL, Kivisäkk P, Cathcart MK, Hesselgesser J, et al. CCR1+/CCR5+ mononuclear phagocytes accumulate in the central nervous system of patients with multiple sclerosis. Am J Pathol 2001;159:1701-10.

57. Thompson KK, Tsirka SE. The diverse roles of microglia in the neurodegenerative aspects of central nervous system (CNS) autoimmunity. Int J Mol Sci 2017;18:504.

58. Bitsch A, Wegener C, da Costa C, Bunkowski S, Reimers CD, et al. Lesion development in Marburg's type of acute multiple sclerosis: from inflammation to demyelination. Mult Scler 1999;5:138-46.

59. Ferguson B, Matyszak MK, Esiri MM, Perry VH. Axonal damage in acute multiple sclerosis lesions. Brain 1997;120:393-9.

60. Trapp BD, Peterson J, Ransohoff RM, Rudick R, Mörk S, et al. Axonal transection in the lesions of multiple sclerosis. N Engl J Med 1998;338:278-85.

61. Reich DS, Lucchinetti CF, Calabresi PA. Multiple sclerosis. N Engl J Med 2018;378:169-80.

62. Bjartmar C, Kinkel RP, Kidd G, Rudick RA, Trapp BD. Axonal loss in normal-appearing white matter in a patient with acute MS. Neurology 2001;57:1248-52.

63. Kornek B, Lassmann H. Axonal pathology in multiple sclerosis. A historical note. Brain Pathol 1999;9:651-6.

64. Lassmann H, van Horssen J. The molecular basis of neurodegeneration in multiple sclerosis. FEBS Lett 2011;585:3715-23.

65. Black JA, Newcombe J, Trapp BD, Waxman SG. Sodium channel expression within chronic multiple sclerosis plaques. J Neuropathol Exp Neurol 2007;66:828-37.

66. Dutta R, Trapp BD. Mechanisms of neuronal dysfunction and degeneration in multiple sclerosis. Prog Neurobiol 2011;93:1-12.

67. Howell OW, Rundle JL, Garg A, Komada M, Brophy PJ, et al. Activated microglia mediate axoglial disruption that contributes to axonal injury in multiple sclerosis. J Neuropathol Exp Neurol 2010;69:1017-33.

68. Peterson JW, Bö L, Mörk S, Chang A, Trapp BD. Transected neurites, apoptotic neurons, and reduced inflammation in cortical multiple sclerosis lesions. Ann Neurol 2001;50:389-400.

69. Pomicter AD, Shroff SM, Fuss B, Sato-Bigbee C, Brophy PJ, et al. Novel forms of neurofascin 155 in the central nervous system: alterations in paranodal disruption models and multiple sclerosis. Brain 2010;133:389-405.

70. Waxman SG. Axonal dysfunction in chronic multiple sclerosis: meltdown in the membrane. Ann Neurol 2008;63:411-3.

71. Calabrese M, Reynolds R, Magliozzi R, Castellaro M, Morra A, et al. Regional distribution and evolution of gray matter damage in different populations of multiple sclerosis patients. PloS One 2015;10:e135428.

72. Ajami B, Bennett JL, Krieger C, McNagny KM, Rossi FM. Infiltrating monocytes trigger EAE progression, but do not contribute to the resident microglia pool. Nat Neurosci 2011;14:1142-9.

73. Huitinga I, van Rooijen N, de Groot CJ, Uitdehaag BM, Dijkstra CD. Suppression of experimental allergic encephalomyelitis in Lewis rats after elimination of macrophages. J Exp Med 1990;172:1025-33.

74. Huitinga I, Damoiseaux JG, Döpp EA, Dijkstra CD. Treatment with anti-CR3 antibodies ED7 and ED8 suppresses experimental allergic encephalomyelitis in Lewis rats. Eur J Immunol 1993;23:709-15.

75. Ransohoff RM. Animal models of multiple sclerosis: the good, the bad and the bottom line. Nat Neurosci 2012;15:1074-7.

76. Denic A, Johnson AJ, Bieber AJ, Warrington AE, Rodriguez M, et al. The relevance of animal models in multiple sclerosis research. Pathophysiology 2011;18:21-9.

77. Dupree JL, Mason JL, Marcus JR, Stull M, Levinson R, et al. Oligodendrocytes assist in the maintenance of sodium channel clusters independent of the myelin sheath. Neuron Glia Biol 2004;1:179-92.

78. Torre-Fuentes L, Moreno-Jiménez L, Pytel V, Matías-Guiu JA, Gómez-Pinedo U, et al. Experimental models of demyelination and remyelination. Neurologia 2017:S0213-4853:30236.

79. Beeton C, Garcia A, Chandy KG. Induction and clinical scoring of chronic-relapsing experimental autoimmune encephalomyelitis. J Vis Exp 2007:224.

80. Kipp M, Nyamoya S, Hochstrasser T, Amor S. Multiple sclerosis animal models: a clinical and histopathological perspective. Brain Pathol 2017;27:123-37.

81. Williams KC, Ulvestad E, Hickey WF. Immunology of multiple sclerosis. Clin Neurosci 1994;2:229-45.

82. Buttermore ED, Thaxton CL, Bhat MA. Organization and maintenance of molecular domains in myelinated axons. J Neurosci Res 2013;91:603-22.

83. Bhat MA, Rios JC, Lu Y, Garcia-Fresco GP, Ching W, et al. Axon-glia interactions and the domain organization of myelinated axons requires neurexin IV/Caspr/Paranodin. Neuron 2001;30:369-83.

84. Dupree JL, Girault JA, Popko B. Axo-glial interactions regulate the localization of axonal paranodal proteins. J Cell Biol 1999; $147: 1145-52$.

85. Ishibashi T, Ikenaka K, Shimizu T, Kagawa T, Baba H. Initiation of sodium channel clustering at the node of Ranvier in the mouse optic nerve. Neurochem Res 2003;28:117-25.

86. Pillai AM, Thaxton C, Pribisko AL, Cheng JG, Dupree JL, et al. Spatiotemporal ablation of myelinating glia-specific neurofascin (Nfasc NF155) in mice reveals gradual loss of paranodal axoglial junctions and concomitant disorganization of axonal domains. J Neurosci Res 2009;87:1773-93.

87. Rasband MN, Peles E, Trimmer JS, Levinson SR, Lux SE, et al. Dependence of nodal sodium channel clustering on paranodal axoglial contact in the developing CNS. J Neurosci 1999;19:7516-28.

88. Rosenbluth J, Dupree JL, Popko B. Nodal sodium channel domain integrity depends on the conformation of the paranodal junction, not on the presence of transverse bands. Glia 2003;41:318-25.

89. Suzuki A, Hoshi T, Ishibashi T, Hayashi A, Yamaguchi Y, et al. Paranodal axoglial junction is required for the maintenance of the Nav1.6-type sodium channel in the node of Ranvier in the optic nerves but not in peripheral nerve fibers in the sulfatide-deficient mice. Glia 2004;46:274-83. 
90. Coman I, Aigrot MS, Seilhean D, Reynolds R, Girault JA, et al. Nodal, paranodal and juxtaparanodal axonal proteins during demyelination and remyelination in multiple sclerosis. Brain 2006;129:3186-95.

91. Zoupi L, Markoullis K, Kleopa KA, Karagogeos D. Alterations of juxtaparanodal domains in two rodent models of CNS demyelination. Glia 2013;61:1236-49.

92. Prinz M, Priller J, Sisodia SS, Ransohoff RM. Heterogeneity of CNS myeloid cells and their roles in neurodegeneration. Nat Neurosci 2011;14:1227-35.

93. Steinman L, Martin R, Bernard C, Conlon P, Oksenberg JR. Multiple sclerosis: deeper understanding of its pathogenesis reveals new targets for therapy. Annu Rev Neurosci 2002;25:491-505.

94. Fife BT, Huffnagle GB, Kuziel WA, Karpus WJ. CC chemokine receptor 2 is critical for induction of experimental autoimmune encephalomyelitis. J Exp Med 2000;192:899-905.

95. Izikson L, Klein RS, Charo IF, Weiner HL, Luster AD. Resistance to experimental autoimmune encephalomyelitis in mice lacking the CC chemokine receptor (CCR)2. J Exp Med 2000;192:1075-80.

96. Buffington SA, Rasband MN. The axon initial segment in nervous system disease and injury. Eur J Neurosci 2011;34:1609-19.

97. Hedstrom KL, Ogawa Y, Rasband MN. AnkyrinG is required for maintenance of the axon initial segment and neuronal polarity. J Cell Biol 2008; 183:635-40.

98. Jenkins SM, Bennett V. Developing nodes of Ranvier are defined by ankyrin-G clustering and are independent of paranodal axoglial adhesion. Proc Natl Acad Sci U S A 2002;99:2303-8.

99. Hartley RK. Differential reactivity of microglia in two mouse models of multiple sclerosis. Theses Diss 2016.

100. Inayat MS, El-Amouri IS, Bani-Ahmad M, Elford HL, Gallicchio VS, et al. Inhibition of allogeneic inflammatory responses by the Ribonucleotide Reductase Inhibitors, Didox and Trimidox. J Inflamm (Lond) 2010;7:43.

101. Matsebatlela TM, Anderson AL, Gallicchio VS, Elford H, Rice CD. 3,4-Dihydroxy-benzohydroxamic acid (Didox) suppresses proinflammatory profiles and oxidative stress in TLR4-activated RAW264.7 murine macrophages. Chem Biol Interact 2015;233:95-105.

102. Turchan J, Pocernich CB, Gairola C, Chauhan A, Schifitto G, et al. Oxidative stress in HIV demented patients and protection ex vivo with novel antioxidants. Neurology 2003;60:307-14.

103. Hamada MS, Kole MH. Myelin loss and axonal ion channel adaptations associated with gray matter neuronal hyperexcitability. J Neurosci 2015;35:7272-86.

104. Evans MD, Dumitrescu AS, Kruijssen DLH, Taylor SE, Grubb MS. Rapid modulation of axon initial segment length influences repetitive spike firing. Cell Rep 2015;13:1233-45.

105. Grubb MS, Burrone J. Activity-dependent relocation of the axon initial segment fine-tunes neuronal excitability. Nature 2010;465:1070-4.

106. Kuba H, Adachi R, Ohmori H. Activity-dependent and activity-independent development of the axon initial segment. J Neurosci 2014;34:3443-53.

107. Paolicelli RC, Bolasco G, Pagani F, Maggi L, Scianni M, et al. Synaptic pruning by microglia is necessary for normal brain development. Science 2011;333:1456-8.

108. Rogers JT, Morganti JM, Bachstetter AD, Hudson CE, Peters MM, et al. CX3CR1 deficiency leads to impairment of hippocampal cognitive function and synaptic plasticity. Version 2. J Neurosci 2011;31:16241-50.

109. Zhan Y, Paolicelli RC, Sforazzini F, Weinhard L, Bolasco G, et al. Deficient neuron-microglia signaling results in impaired functional brain connectivity and social behavior. Nat Neurosci 2014;17:400-6.

110. Coronado VG, McGuire LC, Sarmiento K, Bell J, Lionbarger MR, et al. Trends in traumatic brain injury in the U.S. and the public health response: 1995-2009. J Safety Res 2012;43:299-307.

111. Gardner RC, Yaffe K. Epidemiology of mild traumatic brain injury and neurodegenerative disease. Mol Cell Neurosci 2015;66:75-80.

112. Langlois JA, Rutland-Brown W, Wald MM. The epidemiology and impact of traumatic brain injury: a brief overview. J Head Trauma Rehabil 2006;21:375-8.

113. Taylor CA, Bell JM, Breiding MJ, Xu L. Traumatic brain injury-related emergency department visits, hospitalizations, and deaths United States, 2007 and 2013. MMWR Surveill Summ 2017;66:1-16.

114. Coughlin JM, Wang Y, Minn I, Bienko N, Ambinder EB, et al. Imaging of glial cell activation and white matter integrity in brains of active and recently retired national football league players. JAMA Neurol 2017;74:67-74.

115. Das M, Mohapatra S, Mohapatra SS. New perspectives on central and peripheral immune responses to acute traumatic brain injury. J Neuroinflammation 2012;9:236.

116. Kelley BJ, Lifshitz J, Povlishock JT. Neuroinflammatory responses after experimental diffuse traumatic brain injury. J Neuropathol Exp Neurol 2007;66:989-1001.

117. Morganti-Kossmann MC, Satgunaseelan L, Bye N, Kossmann T. Modulation of immune response by head injury. Injury 2007;38:1392-400.

118. Nizamutdinov D, Shapiro LA. Overview of traumatic brain injury: an immunological context. Brain Sci 2017;7.

119. Velázquez A, Ortega M, Rojas S, González-Oliván FJ, Rodríguez-Baeza A. Widespread microglial activation in patients deceased from traumatic brain injury. Brain Inj 2015;29:1126-33.

120. Coughlin JM, Wang Y, Munro CA, Ma S, Yue C, et al. Neuroinflammation and brain atrophy in former NFL players: an in vivo multimodal imaging pilot study. Neurobiol Dis 2015;74:58-65.

121. Ramlackhansingh AF, Brooks DJ, Greenwood RJ, Bose SK, Turkheimer FE, et al. Inflammation after trauma: microglial activation and traumatic brain injury. Ann Neurol 2011;70:374-83.

122. Zhou Y, Lui YW, Zuo XN, Milham MP, Reaume J, et al. Characterization of thalamo-cortical association using amplitude and connectivity of functional MRI in mild traumatic brain injury. J Magn Reson Imaging 2014;39:1558-68.

123. Boche D, Perry VH, Nicoll JA. Review: activation patterns of microglia and their identification in the human brain. Neuropathol Appl 
Neurobiol. 2013;39:3-18.

124. Engel S, Schluesener H, Mittelbronn M, Seid K, Adjodah D, et al. Dynamics of microglial activation after human traumatic brain injury are revealed by delayed expression of macrophage-related proteins MRP8 and MRP14. Acta Neuropathol 2000;100:313-22.

125. Johnson VE, Stewart JE, Begbie FD, Trojanowski JQ, Smith DH, et al. Inflammation and white matter degeneration persist for years after a single traumatic brain injury. Brain 2013;136:28-42.

126. Engel S, Isenmann S, Ständer M, Rieger J, Bähr M, et al. Inhibition of experimental rat glioma growth by decorin gene transfer is associated with decreased microglial infiltration. J Neuroimmunol 1999;99:13-8.

127. Marklund N. Rodent models of traumatic brain injury: methods and challenges. Methods Mol Biol 2016;1462:29-46.

128. Xiong Y, Mahmood A, Chopp M. Animal models of traumatic brain injury. Nat Rev Neurosci 2013;14:128-42.

129. Donat CK, Scott G, Gentleman SM, Sastre M. Microglial activation in traumatic brain injury. Front Aging Neurosci 2017;9:208.

130. Gensel JC, Zhang B. Macrophage activation and its role in repair and pathology after spinal cord injury. Brain Res 2015;1619:1-11.

131. Kigerl KA, Gensel JC, Ankeny DP, Alexander JK, Donnelly DJ, et al. Identification of two distinct macrophage subsets with divergent effects causing either neurotoxicity or regeneration in the injured mouse spinal cord. J Neurosci 2009;29:13435-44.

132. Loane DJ, Kumar A, Stoica BA, Cabatbat R, Faden AI. Progressive neurodegeneration after experimental brain trauma: association with chronic microglial activation. J Neuropathol Exp Neurol 2014;73:14-29.

133. Jassam YN, Izzy S, Whalen M, McGavern DB, El Khoury J. Neuroimmunology of traumatic brain injury: time for a paradigm shift. Neuron 2017;95:1246-65.

134. Tapp ZM, Godbout JP, Kokiko-Cochran ON. A tilted axis: maladaptive inflammation and HPA axis dysfunction contribute to consequences of TBI. Front Neurol 2019;10:345.

135. Zanier ER, Marchesi F, Ortolano F, Perego C, Arabian M, et al. Fractalkine receptor deficiency is associated with early protection but late worsening of outcome following brain trauma in mice. J Neurotrauma 2016;33:1060-72.

136. Weber MD, McKim DB, Niraula A, Witcher KG, Yin W, et al. The influence of microglial elimination and repopulation on stress sensitization induced by repeated social defeat. Biol Psychiatry 2019;85:667-78.

137. d'Avila JC, Lam TI, Bingham D, Shi J, Won SJ, et al. Microglial activation induced by brain trauma is suppressed by post-injury treatment with a PARP inhibitor. J Neuroinflammation 2012;9:31.

138. Siopi E, Llufriu-Dabén G, Fanucchi F, Plotkine M, Marchand-Leroux C, et al. Evaluation of late cognitive impairment and anxiety states following traumatic brain injury in mice: the effect of minocycline. Neurosci Lett 2012;511:110-5.

139. Eyo UB, Gu N, De S, Dong H, Richardson JR, et al. Modulation of microglial process convergence toward neuronal dendrites by extracellular calcium. J Neurosci 2015;35:2417-22.

140. Garrido-Mesa N, Zarzuelo A, Gálvez J. Minocycline: far beyond an antibiotic. Br J Pharmacol. 2013;169:337-52.

141. Homsi S, Federico F, Croci N, Palmier B, Plotkine M, et al. Minocycline effects on cerebral edema: relations with inflammatory and oxidative stress markers following traumatic brain injury in mice. Brain Res 2009;1291:122-32.

142. Sanchez Mejia RO, Ona VO, Li M, Friedlander RM. Minocycline reduces traumatic brain injury-mediated caspase-1 activation, tissue damage, and neurological dysfunction. Neurosurgery 2001;48:1393-9.

143. Stirling DP, Khodarahmi K, Liu J, McPhail LT, McBride CB, et al. Minocycline treatment reduces delayed oligodendrocyte death, attenuates axonal dieback, and improves functional outcome after spinal cord injury. J Neurosci 2004;24:2182-90.

144. Meythaler J, Fath J, Fuerst D, Zokary H, Freese K, et al. Safety and feasibility of minocycline in treatment of acute traumatic brain injury. Brain Inj 2019;33:679-89.

145. Bye N, Habgood MD, Callaway JK, Malakooti N, Potter A, et al. Transient neuroprotection by minocycline following traumatic brain injury is associated with attenuated microglial activation but no changes in cell apoptosis or neutrophil infiltration. Exp Neurol 2007;204:220-33.

146. Hanlon LA, Raghupathi R, Huh JW. Differential effects of minocycline on microglial activation and neurodegeneration following closed head injury in the neonate rat. Exp Neurol 2017;290:1-14.

147. Lopez-Rodriguez AB, Siopi E, Finn DP, Marchand-Leroux C, Garcia-Segura LM, et al. CB1 and CB2 cannabinoid receptor antagonists prevent minocycline-induced neuroprotection following traumatic brain injury in mice. Cereb Cortex 2015;25:35-45.

148. Simon DW, Aneja RK, Alexander H, Bell MJ, Bayır H, et al. Minocycline attenuates high mobility group box 1 translocation, microglial activation, and thalamic neurodegeneration after traumatic brain injury in post-natal day 17 Rats. J Neurotrauma 2018;35:130-8.

149. Bachstetter AD, Zhou Z, Rowe RK, Xing B, Goulding DS, et al. MW151 inhibited IL-1 $\beta$ levels after traumatic brain injury with no effect on microglia physiological responses. PLoS One 2016;11:e0149451.

150. Witcher KG, Bray CE, Dziabis JE, McKim DB, Benner BN, et al. Traumatic brain injury-induced neuronal damage in the somatosensory cortex causes formation of rod-shaped microglia that promote astrogliosis and persistent neuroinflammation. Glia 2018;66:2719-36.

151. Henry RJ, Ritzel RM, Barrett JP, Doran SJ, Jiao Y, et al. Microglial depletion with CSF1R inhibitor during chronic phase of experimental traumatic brain injury reduces neurodegeneration and neurological deficits. J Neurosci 2020:2402-19.

152. Büki A, Povlishock JT. All roads lead to disconnection?--Traumatic axonal injury revisited. Acta Neurochir (Wien) 2006;148:181-93.

153. Gentleman SM, Nash MJ, Sweeting CJ, Graham DI, Roberts GW. Beta-amyloid precursor protein (beta APP) as a marker for axonal injury after head injury. Neurosci Lett 1993;160:139-44.

154. Johnson VE, Stewart W, Weber MT, Cullen DK, Siman R, et al. SNTF immunostaining reveals previously undetected axonal pathology in traumatic brain injury. Acta Neuropathol 2016;131:115-35.

155. Povlishock JT, Erb DE, Astruc J. Axonal response to traumatic brain injury: reactive axonal change, deafferentation, and neuroplasticity. J Neurotrauma 1992;9:S189-200.

156. Sherriff FE, Bridges LR, Gentleman SM, Sivaloganathan S, Wilson S. Markers of axonal injury in post mortem human brain. Acta 
Neuropathol 1994;88:433-9.

157. Koliatsos VE, Alexandris AS. Wallerian degeneration as a therapeutic target in traumatic brain injury. Curr Opin Neurol 2019;32:786-95.

158. Stoll G, Müller HW. Nerve injury, axonal degeneration and neural regeneration: basic insights. Brain Pathol 1999;9:313-25.

159. Yin TC, Voorhees JR, Genova RM, Davis KC, Madison AM, et al. Acute axonal degeneration drives development of cognitive, motor, and visual deficits after blast-mediated traumatic brain injury in mice. eNeuro 2016;3.

160. Fu R, Shen Q, Xu P, Luo JJ, Tang Y. Phagocytosis of microglia in the central nervous system diseases. Mol. Neurobiol 2014;49:1422-34.

161. Neumann H, Kotter MR, Franklin RJM. Debris clearance by microglia: an essential link between degeneration and regeneration. Brain J Neurol 2009;132:288-95.

162. Bechmann I, Nitsch R. Astrocytes and microglial cells incorporate degenerating fibers following entorhinal lesion: a light, confocal, and electron microscopical study using a phagocytosis-dependent labeling technique. Glia 1997;20:145-54.

163. Wang J, Fox MA, Povlishock JT. Diffuse traumatic axonal injury in the optic nerve does not elicit retinal ganglion cell loss. J Neuropathol Exp Neurol 2013;72:768-81.

164. Holloway OG, Canty AJ, King AE, Ziebell JM. Rod microglia and their role in neurological diseases. Semin Cell Dev Biol 2019;94:96-103.

165. Graeber MB. Changing face of microglia. Science 2010;330:783-8.

166. Cao T, Thomas TC, Ziebell JM, Pauly JR, Lifshitz J. Morphological and genetic activation of microglia after diffuse traumatic brain injury in the rat. Neuroscience 2012;225:65-75.

167. Thomas TC, Ogle SB, Rumney BM, May HG, Adelson PD, et al. Does time heal all wounds? Experimental diffuse traumatic brain injury results in persisting histopathology in the thalamus. Behav Brain Res 2018;340:137-46.

168. Ziebell JM, Taylor SE, Cao T, Harrison JL, Lifshitz J. Rod microglia: elongation, alignment, and coupling to form trains across the somatosensory cortex after experimental diffuse brain injury. J Neuroinflammation 2012;9:247.

169. Bachstetter AD, Rowe RK, Kaneko M, Goulding D, Lifshitz J, et al. The p38 a MAPK regulates microglial responsiveness to diffuse traumatic brain injury. J Neurosci 2013;33:6143-53.

170. Greer JE, Hånell A, McGinn MJ, Povlishock JT. Mild traumatic brain injury in the mouse induces axotomy primarily within the axon initial segment. Acta Neuropathol 2013;126:59-74.

171. Lifshitz J, Kelley BJ, Povlishock JT. Perisomatic thalamic axotomy after diffuse traumatic brain injury is associated with atrophy rather than cell death. J Neuropathol Exp Neurol 2007;66:218-29.

172. Wofford KL, Harris JP, Browne KD, Brown DP, Grovola MR, et al. Rapid neuroinflammatory response localized to injured neurons after diffuse traumatic brain injury in swine. Exp Neurol 2017;290:85-94.

173. Szalay G, Martinecz B, Lénárt N, Környei Z, Orsolits B, et al. Microglia protect against brain injury and their selective elimination dysregulates neuronal network activity after stroke. Nat Commun 2016;7:11499.

174. Eyo UB, Peng J, Murugan M, Mo M, Lalani A, et al. Regulation of physical microglia-neuron interactions by fractalkine signaling after status epilepticus. eNeuro 2017;3.

175. Eyo UB, Gu N, De S, Dong H, Richardson JR, et al. Modulation of microglial process convergence toward neuronal dendrites by extracellular calcium. J Neurosci 2015;35:2417-22.

176. Swiatkowski P, Murugan M, Eyo UB, Wang Y, Rangaraju S, et al. Activation of microglial P2Y12 receptor is required for outward potassium currents in response to neuronal injury. Neuroscience 2016;318:22-33.

177. Dissing-Olesen L, LeDue JM, Rungta RL, Hefendehl JK, Choi HB, et al. Activation of neuronal NMDA receptors triggers transient ATP-mediated microglial process outgrowth. J Neurosci 2014;34:10511-27.

178. Eyo UB, Peng J, Swiatkowski P, Mukherjee A, Bispo A, et al. Neuronal hyperactivity recruits microglial processes via neuronal NMDA receptors and microglial P2Y12 receptors after status epilepticus. J Neurosci 2014;34:10528-40.

179. Greer JE, Povlishock JT, Jacobs KM. Electrophysiological abnormalities in both axotomized and nonaxotomized pyramidal neurons following mild traumatic brain injury. J Neurosci 2012;32:6682-7.

180. Hånell A, Greer JE, Jacobs KM. Increased network excitability due to altered synaptic inputs to neocortical layer $\mathrm{v}$ intact and axotomized pyramidal neurons after mild traumatic brain injury. J Neurotrauma 2015;32:1590-8.

181. Ryu J, Horkayne-Szakaly I, Xu L, Pletnikova O, Leri F, et al. The problem of axonal injury in the brains of veterans with histories of blast exposure. Acta Neuropathol Commun 2014;2:153.

182. Oehmichen M, Theuerkauf I, Meissner C. Is traumatic axonal injury (AI) associated with an early microglial activation? Application of a double-labeling technique for simultaneous detection of microglia and AI. Acta Neuropathol 1999;97:491-4.

183. Schirmer L, Merkler D, König FB, Brück W, Stadelmann C. Neuroaxonal regeneration is more pronounced in early multiple sclerosis than in traumatic brain injury lesions. Brain Pathol Zurich Switz 2013;23:2-12

184. Christman CW, Grady MS, Walker SA, Holloway KL, Povlishock JT. Ultrastructural studies of diffuse axonal injury in humans. J Neurotrauma 1994;11:173-86.

185. Christman CW, Salvant JB, Walker SA, Povlishock JT. Characterization of a prolonged regenerative attempt by diffusely injured axons following traumatic brain injury in adult cat: a light and electron microscopic immunocytochemical study. Acta Neuropathol 1997;94329-37.

186. Harris NG, Mironova YA, Hovda DA, Sutton RL. Pericontusion axon sprouting is spatially and temporally consistent with a growthpermissive environment after traumatic brain injury. J Neuropathol Exp Neurol 2010;69:139-54.

187. Venkatesan C, Chrzaszcz M, Cho N, Wainwright MS. Chronic upregulation of activated microglia immunoreactive for galectin-3/ Mac-2 and nerve growth factor following diffuse axonal injury. J Neuroinflammation 2010;7:32. 